\title{
A APROPRIAÇÃO DA TECNOLOGIA PELA UNIVERSIDADE PÚBLICA BRASILEIRA E O DIÁLOGO ENTRE A INOVAÇÃO E A PROPRIEDADE INDUSTRIAL NO CONTEXTO NACIONAL
}

THE APPROPRIATION OF TECHNOLOGY BY THE BRAZILIAN PUBLIC UNIVERSITY AND THE DIALOGUE BETWEEN INNOVATION AND INDUSTRIAL PROPERTY IN THE NATIONAL CONTEXT LA APROPIACIÓN DE LA TECNOLOGÍA POR LA UNIVERSIDAD PÚBLICA BRASILEÑA Y EL DIÁLOGO ENTRE LA INNOVACIÓN Y LA PROPIEDAD INDUSTRIAL EN EL CONTEXTO NACIONAL

RODRIGO MEIRELES ORTIZ ${ }^{1}$

RECEBIBO 29/01/2019

APROVADO 30/01/2019

PUBLICADO 04/01/2019

Editor Responsável: Carla Caldas

Método de Avaliação: Double Blind Review

E-ISSN: 2316-8080

DOI:10.16928

RESUMO

O presente trabalho pretende analisar a necessidade da apropriação da tecnologia pela universidade pública brasileira, a partir da relação estabelecida entre a inovação e a propriedade industrial no contexto nacional. Isso porque, estudos técnicos demonstram que, embora haja o incremento do potencial inovador nacional, este não acompanha o desenvolvimento efetivo de inovações tecnológicas e, consequentemente, a obtenção de patentes. Além disso, os mesmos números revelam o predomínio da atividade de pesquisa potencialmente inovadora e detentora de eventuais títulos de propriedade industrial pelas universidades públicas, denotando a necessidade de estudos direcionados a estas instituições. Assim, partindo da importância do fortalecimento da cultura da apropriação da tecnologia pela universidade pública, o estudo indica a necessidade de se tratar as atividades de pesquisa e desenvolvimento tecnológico nestas instituições como potencialmente inovadoras e, consequentemente, apropriáveis. Ademais, verifica a importância de um tratamento atento e responsável com o possível patrimônio intangível gerado no seio destas universidades, no intuito de modificar o cenário atual e atender aos mandamentos normativos.

\footnotetext{
${ }^{1}$ Mestrando em Direito e Justiça Social pela Universidade Federal do Rio Grande - FURG. Cidade de Rio Grande, Rio Grande do Sul, Brasil. E-mail: rodrigo_ortiz@hotmail.com.br. Número de identificação no ORCID ID: https://orcid.org/0000-0003-1471-7224.

PIDCC, Aracaju/Se, Ano VIII, Volume 13 no 01, p.082 a 109 Fev/2019 | www.pidcc.com.br
} 
PALAVRAS-CHAVE: Universidade Pública. Propriedade Industrial. Inovação. Apropriação.

\begin{abstract}
The present work intends to analyze the need of the appropriation of the technology by the brazilian public university, starting from the relation established between the innovation and the industrial property in the national context. This is because, technical studies demonstrate that, although there is an increase in the national innovative potential, this does not accompany the effective development of technological innovations, and consequently, the obtaining of patents. In addition, the same numbers reveal the predominance of the potentially innovative research activity and holder of eventual industrial property titles by public universities, denoting the need for studies directed to these institutions. Thus, starting on the importance of strengthening the culture of technology appropriation by the public university, the study indicates the need to treat research and technological development activities in these institutions as potentially innovative and, consequently, appropriable. In addition, it verifies the importance of an attentive and responsible treatment with the possible intangible assets generated within these universities, in order to modify the current scenario and comply with the normative commandments.
\end{abstract}

KEY WORDS: Public University. Industrial Property. Innovation. Appropriation.

\title{
RESUMEN
}

El presente trabajo pretende analizar la necesidad de la apropiación de la tecnología por la universidad pública brasileña, a partir de la relación establecida entre la innovación y la propiedad industrial en el contexto nacional. Esto porque, estudios técnicos demuestran que, aunque existe el incremento del potencial innovador nacional, éste no acompaña el desarrollo efectivo de innovaciones tecnológicas y, consecuentemente, la obtención de patentes. Además, las mismas cifras revelan el predominio de la actividad de investigación potencialmente innovadora y poseedora de eventuales títulos de propiedad industrial por las universidades públicas, denotando la necesidad de estudios dirigidos a estas instituciones. Así, partiendo de la importancia del fortalecimiento de la cultura de la apropiación de la tecnología por la universidad pública, el estudio indica la necesidad de tratar las actividades de investigación y desarrollo tecnológico en estas instituciones como potencialmente innovadoras y, consecuentemente, apropiadas. Además, verifica la importancia de un tratamiento atento y 
responsable con el posible patrimonio intangible generado en el seno de estas universidades, con el fin de modificar el escenario actual y atender a los mandamientos normativos.

PALABRAS CLAVE: Universidad Pública. Propiedad Industrial. Innovación. Apropiación.

\section{INTRODUÇÃO}

No Brasil, atualmente as universidades públicas detêm o predomínio da pesquisa científica e tecnológica, bem como recebem a prioridade do tratamento estatal para o desenvolvimento de novas tecnologias, tornando-se o principal potencial inovador do país. Por conseguinte, dada a consagrada forma de difusão do resultado dos trabalhos pelas universidades, o país ocupa o importante $13^{\circ}$ lugar em publicações científicas no âmbito internacional. E segundo dados do Instituto Nacional de Propriedade Industrial, INPI, entre os dez principais depositantes de patentes residentes no país em 2016, os nove primeiros são universidades públicas.

Contudo, ao lado deste protagonismo universitário, verifica-se no arranjo nacional um potencial inovador que não se traduz na mesma proporção em efetiva inovação, e, por conseguinte, em patentes. Com efeito, em que pese o Brasil atualmente seja o $13^{\circ}$ maior produtor de publicações de pesquisa em nível mundial, ocupa tão somente a $69^{a}$ posição entre 127 países em termos de Inovação. No tocante às patentes, a partir da análise do Tratado de Cooperação em Matérias de Patentes (PCT), verifica-se que o Brasil, em 2017, depositou apenas 593 pedidos, o que representa aproximadamente 1\% dos depósitos efetuados pelo país líder. Ademais, considerados apenas os depósitos efetuados exclusivamente no Brasil, no INPI, verifica-se que $74 \%$ pedidos de 2017 foram depositados por estrangeiros.

Anota-se que visando modificar este cenário e atender ao atual e fático modelo nacional, a Lei de Inovação, Lei no 10.973/04 a Emenda Constitucional da Inovação, EC n ${ }^{\circ}$ 85/2015, e o Marco Legal da Ciência, Tecnologia e Inovação, Lei n ${ }^{0}$ 13.243/2016, para além de incentivarem criações inovadoras, a participação da iniciativa privada e a aproximação entre Universidades e Empresas, impõem a proteção do resultado deste trabalho de pesquisa estimulado pelo Estado, cujo principal instrumento consiste na propriedade industrial.

Dessa forma, a realização do estudo se justifica diante dos dados que demonstram a particularidade nacional, seja pelo domínio da pesquisa estatal, ou ainda pelo significativo protagonismo destas atividades pelas universidades públicas, os quais comprovam a importância de pesquisas que analisem as particularidades deste relevante sujeito da inovação PIDCC, Aracaju/Se, Ano VIII, Volume 13 no 01, p.082 a 109 Fev/2019 | www.pidcc.com.br 
nacional. Além disso, verifica-se a recente mudança constitucional, realizada por meio da Emenda Constitucional $n^{\circ} 85 / 2015$, a qual incluiu entre os temas da ordem social a inovação, bem como afastou a prioridade da pesquisa científica no âmbito nacional, colocando em pé de igualdade a pesquisa tecnológica e a inovação, além de outros instrumentos jurídicos que refletem a política nacional de inovação, como a Lei de Inovação e o Marco Legal da Ciência, Tecnologia e Inovação, o que merece reflexão quanto ao seu impacto no âmbito universitário.

Neste contexto normativo, verifica-se que além de estudos que incentivem a participação da indústria e das empresas no ambiente inovador, bem como a aproximação destas das universidades públicas, há de se dedicar a pesquisas que fomentem ainda mais à proteção daqueles resultados que já são desenvolvidos no âmbito universitário. Com esse último intuito, o presente estudo adota como hipótese deste cenário de contrastes entre o potencial inovador, a efetiva inovação e o número de patentes nacionais, a ausência de cultura da apropriação da tecnologia na universidade pública, seja por se tratarem de instituições públicas, seja pelos textos constitucionais anteriores estabelecerem a liberdade de pesquisa, seja pela tradição da livre difusão e promoção do conhecimento nestas instituições, seja pela forma consolidada de divulgação de seus trabalhos por meio da livre publicação.

Assim, o presente trabalho, realizado em dezembro de 2018, pretende demonstrar a necessidade de apropriação da tecnologia pela universidade pública, a partir do contexto da inovação e do número de patentes nacionais. Com essa finalidade, no primeiro item do estudo se visa comprovar a forte relação entre a inovação, a propriedade industrial e a universidade pública no contexto nacional. Para tanto, inicialmente se busca destacar a importância da inovação na atualidade para o desenvolvimento nacional e para o cumprimento dos objetivos constitucionais e legais. Na sequência, visa-se demonstrar a estreita ligação entre a propriedade industrial e a inovação, a partir dos conceitos estabelecidos pela Lei da inovação, passando pela análise destes elementos como instrumentos de proteção, estímulo e representatividade do desenvolvimento no contexto internacional. Por fim, destaca-se o desempenho geral do país no índice de inovação e no depósito de patentes, e a sua relação direta com as universidades públicas no cenário nacional, diante do arranjo inovador do país.

De posse desses elementos, no segundo item do estudo se busca verificar, como forma de contribuir para a modificação do cenário nacional, a necessidade de apropriação da tecnologia pela universidade pública, por intermédio das patentes, como mudança paradigmática no âmbito da pesquisa e do desenvolvimento universitário. Com esse objetivo, inicialmente são identificadas algumas razões para a dificuldade da absorção cultural da necessidade de apropriação. Na sequência, são levantados fundamentos que buscam amenizar a respectiva PIDCC, Aracaju/Se, Ano VIII, Volume 13 no 01, p.082 a 109 Fev/2019 | www.pidcc.com.br 
dificuldade, iniciando-se com base no texto constitucional, onde se destaca o estímulo ao desenvolvimento, a defesa da soberania, a defesa da propriedade e sua função social, a retirada da prioridade entre a pesquisa científica e tecnológica e a inserção da inovação, além do princípio da eficiência e da legalidade. Após, analisa-se brevemente a liberdade de expressão e a figura do domínio público em face da apropriação para, voltando-se aos textos infraconstitucionais, destacar os elementos que indicam a necessidade de proteção das atividades de pesquisa e de seus resultados inovadores no âmbito universitário.

\section{DIÁLOGO ENTRE INOVAÇÃO, PROPRIEDADE INDUSTRIAL E UNIVERSIDADE PÚBLICA NO CONTEXTO NACIONAL}

$\mathrm{Na}$ atualidade, o conhecimento e a inovação tecnológica consistem em importantes elementos utilizados para a produção de riqueza e bem-estar social, de forma que o estudo das dinâmicas das economias capitalistas nacionais depende da análise da inovação e do desempenho tecnológico dos países. Por conseguinte, diante de novas demandas econômicas e sociais, as nações se veem voltadas à adoção da inovação para sua inserção no mercado internacional competitivo e globalizado, seja pelo reflexo no desenvolvimento do país, seja pela eventual dependência tecnológica estrangeira e comprometimento da soberania.

No Brasil, a Constituição Federal de 1988, além de estabelecer o desenvolvimento nacional como um dos objetivos do Estado no seu art. $3^{\circ}$, II, e de prever a soberania como fundamento estatal no seu art. $1^{\circ}$, I, inaugurou nos seus artigos 218 e 219 a preocupação com a ciência e a tecnologia, atualmente acrescida da inovação, no intuito de concretizar a finalidade constitucional. No ponto, observa-se que a política de desenvolvimento nacional, após algumas fases, tem na atualidade como protagonista o papel da inovação e a busca do desenvolvimento por meio da inovação, o qual, para além das diretrizes de Ciência, Tecnologia e Inovação, passou a irradiar efeitos para outros campos políticos, como a política industrial (Viotti, 2008, p. 3 e 4; Salerno, 2006, p. 16).

Neste contexto, o conceito de inovação passou a se expandir, assumindo um papel central na produção de conhecimento, em detrimento da produção de produtos. Conforme o Manual de Oslo (OCDE, 2006, p. 36), Joseph Schumpeter, apresentando o processo de "destruição criadora", influenciou as teorias da inovação, sobretudo, ao defender que o desenvolvimento econômico é conduzido pela inovação (Oliveira e Avellar, 2009, p. 6). Contribuindo sobre o assunto, Henry Etkowitz (2009) demonstrou um novo arranjo inovador, denominado de tríplice hélice, o qual inclui centros de pesquisa, empresas e governo de forma articulada. E PIDCC, Aracaju/Se, Ano VIII, Volume 13 no 01, p.082 a 109 Fev/2019 | www.pidcc.com.br 
acompanhando estas mudanças, a Lei $\mathrm{n}^{\circ}$ 10.973/2004 regulou o texto constitucional, trazendo no seu atual art. $2^{\circ}, I V$, o conceito de inovação da seguinte forma:

IV - introdução de novidade ou aperfeiçoamento no ambiente produtivo e social que resulte em novos produtos, serviços ou processos ou que compreenda a agregação de novas funcionalidades ou características a produto, serviço ou processo já existente que possa resultar em melhorias e em efetivo ganho de qualidade ou desempenho.

Outras leis também buscam a definição da inovação. A Lei no 11.196/2005, que dispõe sobre incentivos fiscais para a inovação tecnológica, registra a definição no $\S 1^{\circ}$ do art. 17. A Lei Complementar $n^{0}$ 123/2006, que instituiu o estatuto nacional da microempresa e da empresa de pequeno porte, no seu art. 64, I, também define inovação, valendo referir-se, ainda, os conceitos trazidos pelo Manual de Oslo (2006, p. 55) e pelo Manual de Frascati (2007, p. 27). Diante da sua abstração e da ausência de pretensão de se discutir especificamente o conceito neste trabalho, adota-se como variável desta pesquisa o conceito de inovação estabelecido pela Lei no 10.973/2004, e como referência hermenêutica a derivação do adjetivo "novo", presente direta ou indiretamente em todos os conceitos indicados.

Por outro lado, para fins desse estudo, cumpre trazer outra definição do mesmo diploma legal, buscando demonstrar a relevância da inovação tecnológica para o direito de propriedade industrial. Trata-se do conceito de criação, previsto antes do conceito de inovação no $\operatorname{art.} 2^{\circ}$, II, da Lei ${ }^{\circ}$ 10.973/2004, nos seguintes termos:

II - criação: invenção, modelo de utilidade, desenho industrial, programa de computador, topografia de circuito integrado, nova cultivar ou cultivar essencialmente derivada e qualquer outro desenvolvimento tecnológico que acarrete ou possa acarretar o surgimento de novo produto, processo ou aperfeiçoamento incremental, obtida por um ou mais criadores;

Note-se que a própria Lei trouxe os dois conceitos, de inovação e de criação, de forma separada, embora este poderia ser contemplado por aquele. Assim, remete-se à ideia de que a definição legal de inovação consiste em um gênero, do qual a criação seria espécie. Por conseguinte, enquanto a inovação é termo abstrato e teórico, entende-se que a criação, de fato, consiste em um objeto mais concreto da Lei, sobretudo quando relacionada aos demais diplomas legislativos que permitem a apropriação do seu resultado, como a Lei de propriedade industrial. Neste sentido, além da prioridade da menção à criação no texto legal, o art. 12 da mesma Lei $\mathrm{n}^{\mathrm{o}}$ 10.973/2004 expressamente consagra o dever de sigilo a "qualquer aspecto de criações" aos envolvidos em atividades que buscam à inovação, referindo-se à criação como 
inovação em sentido estrito, e não à inovação em sentido amplo e abstrato, demonstrando que o conceito de criação está diametralmente vinculado aos bens passíveis de comercialização e tutelados pelo direito (Tedeschi, 2011, p. 15).

No mesmo sentido, observa-se que, embora as vezes se trate a inovação como atividade, como no conceito do Manual de Frascati (2007, p. 27), o texto legal tende a defini-la como o resultado de uma atividade, como se nota na utilização do substantivo "resulte" no art. $2^{\circ}, \mathrm{IV}$, da Lei 10.973/04. Esse resultado pode ser juridicamente protegido ou não. E para o direito importam aqueles bens que poderão sofrer a eficácia das normas jurídicas, os quais, no caso, se darão por intermédio das Leis de propriedade industrial, guardando relação direta com o conceito de criação, espécie legal de inovação.

Assim, desde logo já se observa a relação entre inovação e propriedade industrial, com base nas definições da Lei da Inovação. De fato, considera-se que o conceito legal de inovação previsto na Lei $\mathrm{n}^{\mathrm{o}} 10.973 / 04$, para além de se relacionar com o resultado de uma atividade, aborda um gênero do qual a criação é espécie. Esta acaba se tornando o objeto mais concreto da Lei, já que os bens mencionados na sua definição legal se encontram protegidos juridicamente por intermédio da Lei de propriedade industrial, tornando-se um resultado apropriável. As atividades, por consequência, são realizadas principalmente pela pesquisa, uma vez que, no seu art. $1^{\circ}$, a Lei $n^{\circ} 10.973 / 04$ define como seu objetivo central o incentivo à inovação e à pesquisa científica e tecnológica. Sem discutir o conceito e suas subdivisões, segundo Paviani e Pozenato (1980, p. 40), “entende-se por pesquisa a investigação metódica e sistemática de um determinado domínio da realidade em estado de problema”. Neste trabalho, apenas se destaca que sem a atividade de pesquisa dificilmente haveria a descoberta de novos conhecimentos, e, consequentemente, de produtos e processos inovadores, denotando, também, o liame entre a pesquisa e a inovação tecnológica.

Por outro lado, anota-se que a propriedade industrial consiste em um dos ramos protegidos pela propriedade intelectual, a qual, para Pimentel (2005, p. 19), representa o “conjunto de princípios e regras que regulam a aquisição, o uso, o exercício e a perda de direitos e de interesses sobre ativos intangíveis diferenciadores que são suscetíveis de utilização no comércio". Segundo a maioria dos autores brasileiros, possui a natureza jurídica de direito real de propriedade (Gusmão, 1990, p. 18 e 20). Os bens móveis estabelecidos e concedidos pela Lei $n^{0} 9.279 / 96$, a qual regulou os direitos de propriedade industrial, permitindo a concessão de títulos temporários de propriedade, inclusive de produtos farmacêuticos, que antes eram vedados pelo antigo Código de Propriedade Industrial (Guerreiro, 2009, p. 241), consagram-se, 
em síntese, nas patentes de invenção e de modelo de utilidade, bem como no registro de desenho industrial e de marca, destacando-se, no presente trabalho, o estudo das patentes, já que proporcionalmente mais vinculados às inovações tecnológicas desenvolvidas nas universidades públicas.

A patente, conforme a Organização Mundial de Propriedade Intelectual, representa um direito exclusivo que se concede sobre uma invenção, facultando a seu titular decidir se esta invenção poderá ser utilizada por terceiros e, neste caso, de que forma (WIPO, 2018a). Com base nos artigos $8^{\circ}$ e $9^{\circ}$ da Lei $n^{\circ} 9.279 / 96$, verifica-se que a patente possui duas espécies, a invenção e o modelo de utilidade, ambos previstos no art. $2^{\circ}$, II, da Lei da inovação, demonstrando, uma vez mais, a estreita ligação entre propriedade industrial e inovação. Por outro lado, em que pese ambos os verbos inovar e inventar estejam atrelados à ideia de mudança de paradigma, sublinha-se que é patenteável a invenção que atenda simultaneamente aos requisitos de novidade, de atividade inventiva e de aplicação industrial, nos termos do art. $8^{\circ}$ da Lei $\mathrm{n}^{\mathrm{o}} 9.279 / 96$, o que denota que nem toda a inovação será patenteável, já que se exige o elemento novo tão somente como um de seus elementos, além de se configurar uma solução técnica para um problema técnico (Barbosa, 2003, p. 297).

A partir deste contexto em cotejo com estes conceitos básicos, convém destacar outros argumentos que demonstram que a inovação tecnológica e a propriedade industrial, sobretudo por meio de patentes, se inter-relacionam no sistema econômico mundial neoliberal. Como anota Barbosa (2010, p. 1), “a ideia por trás do sistema de patentes é de incentivar o investimento em inovação". De fato, uma das maneiras consagradas de intervenção do Estado no fomento e promoção das atividades que buscam à inovação consiste no sistema de proteção de propriedade industrial, o qual se justifica como forma de assegurar os investimentos que visem ao desenvolvimento de novas tecnologias, garantindo um privilégio temporário.

Com efeito, há uma significativa relevância econômica verificada na aquisição de títulos de propriedade desenvolvidos por meio de Pesquisa e Desenvolvimento (P\&D), o que ocorre por meio de produtos e processos inovadores que possam ser objeto de proteção e exclusividade de exploração. Assim, inova-se para se proteger e se protege para inovar, de forma que "o retrato das atividades inovativas de um país aperfeiçoa-se com esse esforço conjunto" (Andreassi et al., 2000, p. 65). As patentes, na verdade, consistem no direito de exploração exclusiva e temporária de uma inovação tecnológica. E esta mesma patente representa a oportunidade de retorno e de "retribuição da sociedade ao esforço inovador" (Albuquerque, 1998, p. 89).

A atratividade inicial para a busca da inovação e a consequente proteção por meio da propriedade intelectual é marcadamente mercadológica, já que se permite em um mercado PIDCC, Aracaju/Se, Ano VIII, Volume 13 no 01, p.082 a 109 Fev/2019 | www.pidcc.com.br 
bastante competitivo a exploração de um determinado produto ou processo inovador em regime de monopólio, sem qualquer competição por um determinado período de tempo, tratando-se de uma exceção à livre iniciativa assegurada pelo Estado. Em decorrência disso, a segurança obtida com a proteção do conhecimento através do sistema de patenteamento apresenta significativa importância na estratégia concorrencial (Pereira, 2011, p. 572). Ademais, na atualidade, a detenção desses títulos de propriedade acaba por refletir o desenvolvimento econômico e social dos países, os quais deixam de ser exportadores de matérias primas e commodities para se tornarem produtores e exportadores de tecnologia, além de autossuficientes em termos tecnológicos.

Por conseguinte, as patentes acabam representando um importante indicador internacional do potencial inovador dos países (Cruz, 2004, p. 12). Na espécie, o Manual de Oslo, utilizado como base e referência usual sobre inovação, estabelece duas famílias fundamentais para a mensuração da inovação. De um lado os recursos direcionados à Pesquisa e Desenvolvimento, e de outro, as estatísticas de patentes (OECD, 2006, p. 29), demonstrando o evidente diálogo entre ambos elementos.

Abordada esta estreita relação, cumpre destacar o diálogo destes dois institutos com as universidades públicas nacionais. A universidade, desde sua origem, teve por fim cultivar e transmitir o saber humano acumulado. Acompanhando o homem em seus processos e estruturas sociais, ela foi se adaptando constantemente às diferentes realidades, prestigiando para o cultivo e difusão do conhecimento o ensino, e para a necessidade de sua ampliação e descoberta, a pesquisa (Wanderley, 1991, p. 37-38).

Neste sentido, a Constituição Federal em seu artigo 207, caput, estabeleceu a indissociabilidade das atividades de pesquisa, ensino e extensão, exigindo a observância dessas tarefas pelas universidades públicas, autarquias em regime especial, segundo a moderna doutrina administrativista (Carvalho, 2016, p. 179), passando-se, assim, a se incentivar fortemente a pesquisa e o desenvolvimento de novos conhecimentos nestas instituições.

E atualmente, voltando os olhos para o arranjo inovador nacional, identificou-se o predomínio da pesquisa científica e tecnológica, do potencial inovador e da obtenção de novos títulos de patente, pelas universidades públicas, de forma oposta a países mais industrializados, nos quais o predomínio se dá pela indústria e por empresas privadas. Ou seja, para além de um potencial inovador, a universidade pública se tornou o principal potencial inovador nacional, e imediatamente, o principal depositante de patentes, denotando a relação fática entre os três elementos. 
De fato, verificou-se que o Brasil se encontra em $13^{\circ}$ lugar como maior produtor de publicações de pesquisa em nível mundial, conquanto a colaboração de coautores da indústria seja de tão somente $1 \%$ dos trabalhos de pesquisa nacionais (Cross et al, 2018, p. 6). O mesmo relatório apontou que as 20 universidades que mais publicam, e revelam a tendência da supremacia da pesquisa, são todas universidades públicas, sendo 16 federais e 4 estaduais (Cross et al, 2018, p. 42).

Ao lado disso, observou-se no país que, além do investimento em pesquisa e desenvolvimento preponderantemente estatal, o percentual dos dispêndios do governo federal foi majoritariamente investido no Ministério da Educação, ao qual estão submetidas as universidades. Em 2015, entre todos os então 39 Ministérios, o MEC foi o destinatário de $60 \%$ do total de recursos em Pesquisa e Desenvolvimento (MCTIC, 2017, p. 36) e 53,2\% dos recursos em Ciência e Tecnologia (MCTIC, 2017, p. 34).

No mesmo sentido, do total de pessoas envolvidas com pesquisa e desenvolvimento no Brasil, segundo os últimos indicadores nacionais de ciência, tecnologia e inovação, 69,9\% estão alocadas no Ensino Superior, 3,3\% no governo e 26,1\% em empresas, contrastando, por exemplo, com a República da Coreia, onde 79,5\% dos pesquisadores trabalham nas empresas, enquanto apenas 12,1\% estão no ensino superior (MCTIC, 2017, p. 146).

Como resultado deste cenário nacional, uma vez mais comprovando o diálogo entre pesquisa, inovação e propriedade industrial, e o consequente protagonismo das universidades públicas no âmbito nacional, anota-se que ao se analisar o número de depósitos de patentes no país, segundo dados do INPI (2017, p. 21), entre os dez principais depositantes de patentes residentes no país em 2016, os nove primeiros são universidades públicas.

Ocorre que, ao lado deste protagonismo das universidades públicas, o qual contribui com a demonstração da vinculação entre inovação e patentes, verifica-se no arranjo nacional um potencial inovador no país que não se traduz na mesma proporção em efetiva inovação, e, por conseguinte, em patentes. Com efeito, em que pese o Brasil atualmente seja o $13^{\circ}$ maior produtor de publicações de pesquisa em nível mundial (Cross et al, 2018, p. 6), ocupa tão somente a $69^{\mathrm{a}}$ posição entre 127 países em termos de Inovação, segundo o Índice Global de Inovação de 2017 (GII, 2017, p.17).

Além do desempenho no índice internacional de inovação, é possível identificar performance semelhante no depósito de patentes, sobretudo quando comparado com países estrangeiros, reforçando o diálogo entre ambos. De fato, a partir do relatório produzido pela Organização Mundial de Propriedade Intelectual (WIPO, 2018b), relativo à análise do Tratado de Cooperação em Matérias de Patentes (PCT), entre os cinco principais países depositantes de PIDCC, Aracaju/Se, Ano VIII, Volume 13 no 01, p.082 a 109 Fev/2019 | www.pidcc.com.br 
patente no mundo, constata-se que o maior depositante de patentes no ano 2017 foi os Estados Unidos, com 56.624 pedidos, seguido por China, com 48.882 pedidos, Japão, com 48.208 pedidos, Alemanha, com 18.982 pedidos, e República da Coreia, com 15.763 pedidos.

Já o Brasil depositou 593 pedidos, o que representa aproximadamente 1\% dos depósitos efetuados pelo país líder (WIPO, 2018b, p. 1). Anota-se que o Brasil aderiu ao PCT em 1978. Ao se consultar a base de dados Patentscope (2018), em maio de 2018, constatou-se que o total de depósitos de pedidos PCT tendo o Brasil como país de origem, em todo o período, somou 7.386 depósitos. Assim, somados todos os depósitos do Brasil durante os 40 (quarenta) anos em que aderiu ao Protocolo, verifica-se que o país, com os seus 7.386 depósitos, não alcança metade dos depósitos da Coreia em um único ano, ou ainda, não alcança 14\% dos depósitos dos EUA também em um único ano.

No mesmo sentido, ainda que considerados apenas os depósitos efetuados exclusivamente no Brasil, no Instituto Nacional de Propriedade Industrial, também se verifica uma desarmonia. No ponto, com base nos Indicadores Nacionais de Ciência, Tecnologia e Inovação (MCTIC, 2017, p. 113), constata-se que, no Brasil, foram depositados no INPI 31.020 pedidos de patentes no ano de 2017. Deste total, apenas 8.082 foram depositados por residentes no país, enquanto 22.938, ou seja, 74\%, foram depositados por estrangeiros.

Dessa forma, conquanto se verifique que o Brasil publica de forma relevante, possui um número expressivo de pesquisadores, tem uma das maiores economias, populações e território do mundo, e investe de forma expressiva, embora ainda não desejável, em pesquisa, constatase que o país deixa a desejar na hora de transformar essa pesquisa em inovações tecnológicas e, consequentemente, em patentes.

Buscando amenizar este cenário nacional, e atender aos objetivos normativos, a Lei da Inovação, Lei no 10.973/04 a Emenda Constitucional da Inovação, EC nº 85/2015, e o Marco Legal da Ciência, Tecnologia e Inovação, Lei $n^{0}$ 13.243/2016, para além de incentivarem criações inovadoras, a participação da iniciativa privada e a aproximação entre Universidades e Empresas, impõem a proteção do resultado deste trabalho de pesquisa estimulado pelo Estado, cujo principal instrumento consiste na propriedade industrial.

No mesmo sentido, a análise do texto constitucional, relativo à tecnologia e à inovação, da Lei de Inovação e da Lei de propriedade industrial, denota que todos dispositivos convergem para um mesmo objetivo, qual seja, o desenvolvimento tecnológico nacional, como no caso do art. 5, XXIX, e art. 218, 219, 219-A e 219-B, da CF, o art. 2º caput, da Lei 9.279/96, e, por exemplo, o art. $1^{\circ}$, caput, parágrafo único, I e II da Lei $\mathrm{n}^{\circ} 10.973 / 04$, modificada pela Lei PIDCC, Aracaju/Se, Ano VIII, Volume 13 no 01, p.082 a 109 Fev/2019 | www.pidcc.com.br 
13.243/2016, o qual passa pela apropriação de tecnologias nacionais e pela diminuição da dependência da tecnologia estrangeira.

Assim, verifica-se a relação existente entre a propriedade industrial, a inovação e a universidade pública no país, bem como o protagonismo das atividades que repercutem naqueles resultados nestas instituições, e o potencial inovador nacional que não se traduz em inovação tecnológica e em títulos de patente. Consequentemente, observa-se a importância da apropriação da inovação pelas universidades públicas, e consequentemente da tecnologia desenvolvida, por meio da propriedade industrial, seja para o desenvolvimento social e econômico do país, seja para a mitigação da dependência da tecnologia estrangeira, ou ainda na busca do cumprimento dos fins exigidos e perseguidos pela legislação e pela política nacional.

\section{DA APROPRIAÇÃO DA TECNOLOGIA PELA UNIVERSIDADE PÚBLICA BRASILEIRA}

Como analisado, no país, voltando os olhos para o arranjo inovador nacional, identificase o predomínio da pesquisa, do potencial inovador e da obtenção de novos títulos de patente pelas universidades públicas, o que impõe um novo olhar sobre o assunto. Com efeito, para além de trabalhos que incentivem a participação da indústria e das empresas no ambiente inovador, bem como a aproximação destas das universidades públicas, identifica-se a necessidade de pesquisas que fomentem ainda mais à proteção daqueles trabalhos que já são desenvolvidos no âmbito universitário, sendo este o intuito do presente estudo.

No ponto, observa-se que as universidades públicas, por se tratarem de instituições públicas, de forma habitual tem suas atividades vinculadas a ideia de coisa pública, em oposição à coisa privada, o que já aponta para eventuais dificuldades interpretativas relativas à apropriação do resultado por meio da propriedade industrial. Soma-se o fato de que na história constitucional brasileira os textos anteriores à Constituição de 1988 tratavam fundamentalmente da liberdade da ciência e do dever do Estado no apoio à pesquisa (Barbosa, 2015, p. 12), sem a efetiva preocupação com o desenvolvimento tecnológico, o que não foi reproduzido pelo texto atual.

Ademais, tradicionalmente a universidade consiste na livre difusora e promotora do conhecimento, sem vocação voltada ao atendimento das necessidades do mercado, o que consequentemente representa naturais dificuldades no desenvolvimento e na consequente apropriação da tecnologia, realizada por intermédio de suas pesquisas, e que se dá sobretudo por meio da propriedade industrial. 
Além disso, registra-se que o adjetivo atribuído ao título, de propriedade "industrial", somado à previsão na Constituição Federal no artigo $5^{\circ}$, incisos XXVII, XXVIII e XXIX, da propriedade industrial entre o rol das garantias fundamentais do homem (Basso, 2008, p. 39), e ao adequado estudo de forma mais específica no âmbito do direito empresarial (Barros, 2016, p. 143), já que com clara vocação para proteção de interesses privados, notadamente de indivíduos, empresas e indústrias, contrastam com o arranjo fático nacional e com o predomínio das universidades públicas nesta atividade, fomentando o debate.

Neste trabalho não se discutirá os fundamentos filosóficos da propriedade, sobretudo no tocante à propriedade industrial, já que neste caso a escassez, ao contrário dos bens naturais, é determinada pelo Estado. Tão somente se afasta a expressão original, inspirada no princípio do Homestead Act, e adota-se como diretriz da apropriação a passagem do objeto sem dono para o estado de domínio de alguém. Ademais, no presente estudo não se pretende discutir especificamente o papel da universidade. Contudo, diante do diálogo entre inovação e propriedade industrial, em comparação ao desempenho inovador nacional, lança-se o foco a este importante sujeito do sistema de inovação brasileiro, identificando, neste estudo, a necessidade de apropriação da tecnologia inovadora, no intuito de contribuir para uma mudança cultural que vise ao estímulo e ao adequado tratamento do potencial inovador e da propriedade industrial (Bonacelli et al, 2016, p. 129) como bem público. Na espécie, apenas se destaca que, conquanto não esteja especificamente entre as suas atividades, o contexto fático atual denota a preponderância da universidade na pesquisa tecnológica, não havendo como negar a sua importância no desenvolvimento social, econômico e tecnológico do país.

Por conseguinte, presume-se, para a efetiva realização dos objetivos constitucionais, para o atendimento das finalidades normativas e para a mudança fática do desempenho nacional, a necessidade de proteção das atividades desenvolvidas nas universidades públicas, consolidando-se a mudança cultural e o contexto da pesquisa e da inovação tecnológica. E neste trabalho, uma das sugestões para a busca desta finalidade e estímulo ainda maior para a obtenção de resultados e títulos consiste na difusão da necessidade de apropriação da tecnologia, sobretudo por meio da propriedade industrial.

Com efeito, a Constituição contemporânea além de não tratar mais da liberdade de pesquisa, por meio dos artigos 218, 219, 219-A e 219-B reforça a necessidade de desenvolvimento científico, por meio da pesquisa e capacitação científica de um lado, e do desenvolvimento tecnológico, por meio da pesquisa e capacitação tecnológica, de outro, além da inovação. Prestigia-se, assim, o princípio do desenvolvimento, característico da terceira PIDCC, Aracaju/Se, Ano VIII, Volume 13 no 01, p.082 a 109 Fev/2019 | www.pidcc.com.br 
geração e estabelecido no art. $3^{\circ}$, II, da CF, bem como a soberania nacional, elemento do Estado extraído do art. $1^{\circ}$, I, da CF. Inclusive, como mencionado, cotejando o texto constitucional relativo à tecnologia e à inovação, com a Lei de propriedade industrial e com a Lei de Inovação, verifica-se que todos convergem para o desenvolvimento tecnológico nacional, o qual necessariamente há de ser protegido.

Ademais, o texto constitucional indica uma possível diferença didática da atividade científica, a qual se presume não apropriável, da atividade tecnológica e da inovação, estas sim presumivelmente objetos de apropriação, embora, na prática, estas atividades possam se confundir. Respectiva preocupação constituinte que reflete a faculdade de apropriação é reforçada pela previsão do art. $5^{\circ}$, XXIX, da CF, ao estabelecer a possibilidade da propriedade industrial, embora condicionada ao interesse social e ao desenvolvimento tecnológico e econômico do país, bem como a propriedade privada, a qual também constitui fundamento da ordem econômica, condicionada a sua função social, conforme art. 5 , XXII e XXIII, e art. 170, II e III, todos da CF. Sem a efetiva apropriação das tecnologias desenvolvidas, o país faculta o não atendimento das finalidades constitucionais estabelecidas e permite a agentes externos a apropriação do resultado produzido com esforço de todos.

Além da teórica distinção das atividades científicas e tecnológicas que deixam de ter prioridade entre si, da busca à inovação, ao desenvolvimento nacional e à soberania, bem como a atenção dada à função social da propriedade e ao interesse social, invoca-se como fundamento da apropriação o princípio da eficiência, estabelecido no caput do artigo 37 da Constituição. Isso porque, sem a apropriação do resultado do trabalho público, além de se permitir o desperdício de recursos públicos, não haveria qualquer retorno do investimento estatal, tão pouco a efetiva destinação a sua finalidade, uma vez que se facultaria que a mesma sociedade pagasse, ou eventualmente importasse, a tecnologia que ela mesma produziu ou contribuiu para seu desenvolvimento, impedindo a concretização do mandamento constitucional.

Analisando os textos infraconstitucionais, para problematização do assunto, adota-se como exemplo prático e emblemático o fato de que uma das formas consolidadas para avaliação da produção técnica das Universidades ainda consiste na publicação de trabalhos científicos, o que consequente se traduz na busca e na divulgação de novos conhecimentos em livros, periódicos e revistas especializadas. Contudo, como é cediço, a publicação destas informações pode afetar a proteção da invenção, já que a Lei n ${ }^{\circ} 9.279 / 96$ exige no seu artigo $8^{\circ}$ o atendimento dos requisitos de novidade, atividade inventiva e aplicação industrial. Especificamente com relação ao requisito novidade, este é considerado pela Lei como aquilo que não está 
compreendido no estado na técnica, ou seja, acessível ao público de forma escrita ou oral, antes da data de depósito do pedido de patente, conforme art. 11, caput e $\S 1^{\circ}$, da Lei ${ }^{\circ}$ 9.279/96.

Por conseguinte, observa-se um aparente paradoxo consistente no fato de que, embora exista o fomento da publicação científica no seio Universitário, esta mesma publicação pode inviabilizar a proteção da propriedade industrial já que, no momento da publicação, elimina-se o requisito novidade. Além de se tratar de um método destacado de avaliação da produção científica, verifica-se como fundamento para a publicação, em diálogo com a defesa da não apropriação, o argumento de vocação principal da ciência ao domínio público, sobretudo em razão da redação original do artigo $218, \S 1^{\circ}$ da $\mathrm{CF}$, que priorizava a pesquisa científica. Além disso, invoca-se a liberdade de expressão, prevista no art. $5^{\circ}$, IX, da CF.

No ponto, cumpre destacar que a resistência à tese de vocação única do domínio público da pesquisa já era sustentada no $\S 2^{\circ}$ do artigo 218 da $\mathrm{CF}$, o qual já estabelecia a ideia de apropriação da tecnologia, sobretudo de forma a solucionar problemas nacionais e desenvolver o sistema produtivo interno e regional, sob pena de se permitir o favorecimento do setor produtivo estrangeiro. De qualquer forma, a Emenda Constitucional $n^{\circ} 85 / 2015$ modificou o artigo 218 da CF, retirando a prioridade existente e prevendo, em igualdade de condições, a inovação e a pesquisa científica e tecnológica, sendo a inovação e a pesquisa tecnológica, em regra, destinadas à solução de um determinado problema técnico, e, consequentemente, apropriável. Extrai-se, assim, a possibilidade da apropriação dos resultados das pesquisas no âmbito constitucional, cogitando-se, inclusive, como regra, embora isto não seja sinônimo de que não haja exceções. Nesse sentido, os ensinamentos de Barbosa (2015, p. 22):

Assim, não se consagra mais na Constituição que a Ciência básica financiada pelo estado destina-se ao domínio público, e a tecnologia à apropriação. É uma vitória dos patrimonialistas: mantido em sigilo, resguardado, o saber científico agora pode (o que não significa que deva ou seja em todos casos) excluído do domínio comum.

Com efeito, é fato que a própria Constituição, no art. $5^{\circ}$, IX, estabeleceu a liberdade de expressão da atividade científica, independente de censura ou licença. Contudo, a própria constituição, em seus artigos 218, 219, 219-A e 219-B, para além de prever em igualdade de condições a pesquisa científica e tecnológica, a qual na prática muitas vezes não é de fácil distinção, afastou a prioridade anterior e inclui a inovação entre seus temas. Uma interpretação sistemática e histórica dos dispositivos constitucionais pode conduzir à presunção de que permanece livre a publicação da pesquisa científica, não apropriável, a qual deve ser diferenciada da pesquisa tecnológica, cujos resultados inovadores são efetivamente PIDCC, Aracaju/Se, Ano VIII, Volume 13 no 01, p.082 a 109 Fev/2019 | www.pidcc.com.br 
apropriáveis, sobretudo por meio da propriedade industrial. O que não mais se pode afirmar, com base no texto constitucional que além de igualar as atividades incluiu a inovação entre seus temas, é a presunção de que a pesquisa seja científica, o que conduz a necessidade de tratamento da atividade e de seus resultados como possivelmente tecnológicos e inovadores, já que o fruto desta atividade pode ser afetado caso não adequadamente protegido. Tão pouco se pode, diante do cenário nacional, ignorar que dado o protagonismo de uma instituição pública, esta submetese a regime jurídico próprio, visando ao interesse coletivo, ao qual estão vinculados os servidores que nela atuam.

Frisa-se que a tensão existente entre domínio público e direito de exclusividade, como a propriedade industrial, é consequência natural da inclinação à escolha política e econômica dos Estados para o desenvolvimento tecnológico. Segundo Barbosa (2005, p. 4 e 5):

\footnotetext{
Das muitas formas possíveis de estímulo ao investimento criativo, a história real das economias de mercado inclinou-se por um modelo específico: aquele que dá ao criador ou investidor um direito de uso exclusivo sobre a solução tecnológica, ou sobre a obra do espírito produzida.

(...)

Nas situações em que a criação é estimulada ou apropriada pelo mercado, duas hipóteses foram sempre suscitadas:

a) ou a da socialização dos riscos e custos incorridos para criar;

b) ou a apropriação privada dos resultados através da construção jurídica de uma exclusividade artificial, como a da patente, ou do direito autoral, etc.. É desta última hipótese que falamos inicialmente como sendo o modelo preferencial das economias de mercado.
}

No particular, relembra-se que a discussão acerca do domínio público nasce quando o direito estatal passa a limitar o uso de criações. Previamente à apropriação da tecnologia e ao direito de exclusividade, não se falava em domínio público e privado. Conforme afirma Barbosa (2011, p. 14) "antes de se criarem patentes, direitos exclusivos de autor, ou monopólios de exploração de variedades de rosas, tudo era de domínio público, e assim a questão era indistinta". Dessa forma, a alegação de domínio público, ao contrário do que possa parecer, surge no século XIX visando limitar o prazo de apropriação e exclusividade do direito autoral. Por conseguinte, caíam em domínio público as obras apropriadas que ultrapassassem o prazo de proteção legal, o que é reconhecido até hoje.

Buscando definir as suas características, Barbosa (2005. p. 10), afirma que "o ingresso no domínio público em cada sistema jurídico é incondicional, universal e definitivo; a criação passa a ser comum de todos, e todos têm o direito de mantê-la em comunhão, impedindo a apropriação singular". O conceito, contudo, ainda não é pacífico, conforme afirma Hely Lopes Meirelles, a partir da doutrina administrativa (2016, p. 633): 


\begin{abstract}
O conceito de domínio público não é uniforme na doutrina, mas os administrativistas concordam em que tal domínio, como direito de propriedade, só é exercido sobre os bens pertencentes às entidades públicas e, como poder de Soberania interna, alcança tanto os bens públicos como as coisas particulares de interesse coletivo.

A expressão domínio público ora significa o poder que o Estado exerce sobre os bens próprios e alheios, ora designa a condição desses bens.

A mesma expressão pode ainda ser tomada como conjunto de bens destinados ao uso público (direto ou indireto - geral ou especial - uti singuli ou uti universia) como pode designar o regime a que se subordina esse complexo de coisas afetadas de interesse público.
\end{abstract}

Nesse sentido, o domínio público da pesquisa e da inovação deve ser entendido não como algo exclusivamente de domínio estatal. Para além daquilo que é de uso geral e livre, constituise, sobretudo, por aquilo que é não apropriável (Barbosa, 2011, p. 19). E no ponto, evidentemente que o resultado das pesquisas tecnológicas desenvolvidas na universidade pública é apropriável por meio da propriedade industrial. Recorda-se que o Estado, por meio da Constituição Federal, no art. 5, XXIX, e a Lei de propriedade industrial, Lei $n^{\circ}$ 9.279/96, afastam as criações do domínio público e estabelecem a apropriação destes bens. E assim se destaca que, na verdade, a criação tecnológica apropriável somente cai em domínio público após a extinção da patente, nos termos do parágrafo único do art. 78 da Lei 9.279/96.

Não se ignora a defesa do domínio público de toda a tecnologia, bem como o importante posicionamento acerca do qual uma patente configura uma limitação legal à livre iniciativa e à livre concorrência, prejudicial à sociedade e aos consumidores (Ramos et al, 2016, p. 30). Contudo, enquanto existente o sistema de proteção, e consequentemente, enquanto permitida a apropriação deste bem, para atender aos fins exigidos pela Constituição e pela Lei, entende-se que se impõe a efetiva proteção.

Relembra-se, ainda, que a respectiva apropriação não impede a utilização de outras formas de distribuição e acesso livre da tecnologia, tais como a autorização e o licenciamento gratuito. Contudo, conforme se observa, a apropriação não se confunde com domínio público, já que, como bem apropriável, deverá ser objeto de proteção para posterior disposição livre ou limitada, de acordo com o interesse público.

Além destes argumentos, verificando-se o artigo 88 da Lei n ${ }^{\circ} 9.279 / 96$, constata-se que a propriedade industrial, desenvolvida no âmbito universitário com a utilização de recursos públicos e em decorrência do exercício das atribuições do cargo de seus servidores, é da pessoa jurídica, e consequentemente, da universidade pública. De fato, as universidades públicas, ao prestarem um serviço público na busca do atendimento de uma necessidade coletiva, oferecem 
os meios e equipamentos para a realização da pesquisa e do desenvolvimento de tecnologias. Seus docentes e pesquisadores, mediante relação estatutária ou contratual, são remunerados para o desenvolvimento dessas atribuições, já que além do ensino, exercem as atividades de pesquisa e de extensão de forma indissociável, nos termos do artigo 207, da Constituição Federal. Por conseguinte, o resultado dessa atividade, em regra, se torna um bem público, ao qual incide regime jurídico específico, o que já denotaria a discussão acerca da possibilidade de divulgação de informações pelo pesquisador público de maneira espontânea diante do eventual prejuízo ao requisito legal para apropriação do resultado final.

Com efeito, entende-se como bem público aquele pertencente às pessoas jurídicas de Direito Público, nos termos do artigo 98 do Código Civil, bem como aqueles que, embora não pertencentes a estas pessoas, estejam afetos à prestação de uma atividade pública (Mello, 2013, p. 929). Conforme ensina Di Pietro (2014, p. 748), a natureza jurídica da propriedade pública, conquanto não seja distinta na essência da propriedade privada, possui características próprias em razão da afetação dos bens, destacando-se a alienação condicionada, a impenhorabilidade, a imprescritibilidade e a não oneração. A existência deste regime jurídico próprio aos bens públicos visa assegurar a continuidade do serviço público e a supremacia do interesse público, além de atender aos princípios centrais da administração de legalidade, impessoalidade, moralidade, publicidade e eficiência, conforme art. 37 da $\mathrm{CF}$, denotando o cuidado ao patrimônio público, seja pelo administrador ou pelo servidor que utiliza a coisa pública, limitando a sua livre disposição para o cumprimento da finalidade coletiva.

No ponto, como já mencionado, embora não esteja especificamente entre as suas atividades, o contexto fático denota a preponderância da universidade na pesquisa tecnológica, não havendo como negar a sua importância no desenvolvimento econômico, social e tecnológico do país. Consequentemente, impõe-se o tratamento dos recursos que são utilizados para a realização da pesquisa e desenvolvimento de novas tecnologias como uma atividade pública potencialmente apropriável, exigindo do administrador e dos agentes públicos envolvidos o adequado tratamento do patrimônio público no interesse de todos. Este olhar diante da realidade nacional e do tratamento jurídico dado ao bem público, indica a necessidade do desenvolvimento e da proteção dos ativos intelectuais, os quais devem ser adequadamente acompanhados e tratados como qualquer outro bem físico de propriedade da instituição.

Da mesma forma, ao se abordar a relação estatal estabelecida entre servidores públicos e bens públicos, há a incidência das duas pedras de toque do direito administrativo, quais sejam, a supremacia do interesse público, caracterizada pela prevalência do interesse coletivo sobre o individual, e a indisponibilidade do interesse público, as quais também delimitam o poder PIDCC, Aracaju/Se, Ano VIII, Volume 13 no 01, p.082 a 109 Fev/2019 | www.pidcc.com.br 
administrativo impedindo a livre disposição do agente. Além destes parâmetros que vinculam o agente estatal, verifica-se a incidência de deveres administrativos com o patrimônio público que também restringem a atividade dos servidores, tais como o de zelo, atendido por meio de comportamentos e do cumprimento dos objetivos preestabelecidos de eficiência; de eficiência, o qual exige do agente público o melhor resultado possível com o mínimo da aplicação de recursos; de controle, configurado no adequado acompanhamento da aplicação e guarda dos recursos e bens públicos; e o dever de prestar contas na gestão e utilização dos bens e interesses da coletividade, o que repercute, no caso analisado, no desenvolvimento das pesquisas potencialmente protegidas.

Nestes dois últimos pontos, destaca-se que o recente Decreto $\mathrm{n}^{\circ}$ 9.283/2018, ao regular a Lei de Inovação, expressamente prevê o capítulo VII, "Da Prestação de Contas”, estabelecendo medidas de monitoramento e avaliação constante da atividade de desenvolvimento, bem como regulando a prestação de contas final, em uma clara preocupação com a atividade potencialmente apropriável. Anota-se que respectivos deveres prestigiam a administração pública gerencial, corolário das modificações tecnológicas e da atual organização econômica e política mundial, de forma a permitir ao Estado a competição com outros países diante da globalização. Respectiva orientação foi valorizada pelo Plano Diretor da Reforma do Aparelho do Estado lançado em 1995, culminando com a Emenda Constitucional no 19/1998 e paulatinamente tem substituindo a administração burocrática, voltada ao controle de processos, para uma administração gerencial, dedicada ao controle de resultados (Mafra, 2005). Assim, destaca-se que a vinculação do agente público a determinadas balizas não pretende o engessamento de suas atividades, justamente atacado pela administração gerencial, mas sim o cuidado e o comprometimento com o resultado daquelas atividades.

Dessa forma, tendo em vista que para a realização da pesquisa tecnológica há a utilização de recursos públicos e de servidores públicos, bem como que o resultado desta atividade pode contribuir para o desenvolvimento e soberania nacional, o tratamento deste potencial, desde o início, como eventual patrimônio público já denota a necessidade de cuidado e eventual proteção, consagrando o princípio da apropriação.

Além destes mandamentos decorrentes do regime jurídico do bem público e da relação entre o patrimônio público e os agentes estatais, outro elemento significante para o acolhimento do princípio da apropriação consiste nas determinações de sigilo dos envolvidos pelo legislador ordinário, o que consagra o princípio de confidencialidade da atividade de pesquisa e 
desenvolvimento de tecnologia, protegido no âmbito civil, administrativo e penal, na busca de se resguardar a novidade e garantir o direito de propriedade (Bochino et al, 2010, p. 193).

No particular, relembra-se que a Constituição Federal estabelece hipóteses de exceções ao princípio da publicidade, como previsto nos artigos $5^{\circ}$, XIX, XXXIII, XXXIV e LX indicando a possibilidade de sigilo diante do interesse público. O Acordo TRIPS, incorporado ao ordenamento jurídico nacional pelo Decreto $\mathrm{n}^{\mathrm{o}} 1.355 / 94$, no seu art. 39 , estabelece a viabilidade da proteção da informação confidencial. A Lei de acesso à informação, Lei $n^{o}$ $12.527 / 11$, expressamente protege o sigilo dos projetos de pesquisa e desenvolvimento científicos ou tecnológicos, conforme artigo $7^{\circ}, \S 1^{\circ}$, artigo 22 e inciso VI do artigo 23. A Lei $n^{\circ}$ 9.279/96 consigna no art. 195, XI e XII hipóteses de crime de concorrência desleal decorrente da divulgação sem autorização de informações, obtidos em decorrência da atividade exercida ou de forma ilícita. Recorda-se que o art. 116, VIII, da Lei 8.112/90 estabelece ao servidor público o dever de sigilo sobre assunto da repartição e o artigo 325 do Código Penal estabelece o tipo penal de violação de sigilo funcional àquele que revelar fato de que tiver ciência em razão do cargo ou que deva permanecer em segredo, cujos agentes ativos são estendidos pela norma do artigo 327 do mesmo diploma.

Além destes dispositivos que já permitiriam a discussão do assunto, e denotariam a mudança paradigmática de abordagem da apropriação da tecnologia em face do domínio público e da livre difusão de informações, o artigo 12 da Lei $\mathrm{n}^{\circ}$ 10.973/04, de forma expressa, estabeleceu, uma vez mais, o dever de confidencialidade de qualquer aspecto da criação desenvolvida na universidade. Observe-se o seu teor:

Art. 12. É vedado a dirigente, ao criador ou a qualquer servidor, militar, empregado ou prestador de serviços de ICT divulgar, noticiar ou publicar qualquer aspecto de criações de cujo desenvolvimento tenha participado diretamente ou tomado conhecimento por força de suas atividades, sem antes obter expressa autorização da ICT.

A norma exige a autorização expressa da Universidade para divulgação de aspectos da criação em desenvolvimento ou desenvolvida por qualquer um de seus envolvidos, o que pode afetar diretamente as práticas até então adotadas no âmbito universitário. Assim, consagra-se, com base neste dispositivo legal, e nos anteriores analisados, o princípio da confidencialidade.

Contudo, de forma lógica, incide o dever de confidencialidade visando a uma finalidade. E no caso, a finalidade mais ostensiva consiste na proteção do eventual resultado final, o que concretiza o princípio da apropriação. Consequentemente, um princípio é meio e fundamento para a concretização do outro. 
De qualquer sorte, para fins deste trabalho, destaca-se que, vinculando-se a inovação e as atividades voltadas para este resultado, sobretudo por meio da pesquisa, à propriedade industrial, há uma mudança paradigmática acerca da apropriação da tecnologia, sobretudo no âmbito universitário, principal potencial inovador do país, cuja orientação como princípio deverá nortear os agentes públicos e os intérpretes das normas na realização das atividades intermediárias para obtenção da tecnologia.

Sublinha-se, que nada impede que uma vez protegida e apropriada a tecnologia seja livremente acessada e oferecida, já que, como abordado por Dênis Barbosa (2015, p. 21), "apropriação não quer dizer denegar acesso". Ademais, anota-se que não há princípios absolutos, os quais devem ser aplicados com parcimônia e ponderação quando em conflito com outros princípios. O que se observa é que os mandamentos normativos analisados, como o dever de sigilo determinado pelo legislador, consagram uma finalidade, da qual decorre o princípio da apropriação. E o atendimento a estes diplomas, acaba consagrando o princípio da legalidade, estabelecido no caput do art. 37 da CF.

Em síntese, observa-se que por uma interpretação lógica, sistemática e teleológica do ordenamento jurídico, a partir da busca do desenvolvimento e da soberania nacional, previstos no artigo $3^{\circ}$, II e artigo $1^{\circ}$, I, concretizados por meio dos artigos 218, 219, 219-A e 219-B, todos da CF; pela observância dos princípios da legalidade e da eficiência, estabelecidos no caput do artigo 37 da CF; em decorrência da importância do atendimento da propriedade industrial a uma finalidade social, decorrente do art. $5^{\circ}$, XXIX, XXII, XXIII e art. 170, II e III, todos da CF; pela previsão do art. 88, da Lei $\mathrm{n}^{\circ}$ 9.729/96, o qual fundamenta a propriedade da universidade pública e consequentemente origina um bem público em que incide regime jurídico específico; tendo em vista a incidência dos princípios da supremacia e indisponibilidade do interesse público, bem como os deveres administrativos de zelo, eficiência, controle e prestação de contas na utilização e guarda de recursos públicos ao agentes públicos limitando a atuação dos agentes públicos; pela tendência de prestígio à administração pública gerencial, voltada ao controle de resultados, em detrimento da administração pública burocrática, focada no controle dos processos; pela imposição do sigilo das informações, decorrente do artigo $5^{\circ}$, XIX, XXXIII, XXXIV e LX, da CF, do art. 39 do TRIPS, dos artigos $7^{\mathrm{o}}, \S 1^{\mathrm{o}}, 22$ e, 23, VI, da Lei $\mathrm{n}^{\mathrm{o}}$ 12.527/2011, do art. 195, XI e XII, da Lei $\mathrm{n}^{\circ}$ 9.279/1996, do artigo 116, VIII, da Lei 8.112/90, do artigo 327 do CP, e atualmente, de forma mais específica, do artigo 12 da Lei $n^{\circ} 10.973 / 2004$, exigindo a confidencialidade dos aspectos da eventual criação e a necessidade de autorização das instituições para sua divulgação; infere-se a PIDCC, Aracaju/Se, Ano VIII, Volume 13 no 01, p.082 a 109 Fev/2019 | www.pidcc.com.br 
necessidade de apropriação da tecnologia, o que, como regra, deve-se se sobressair ao domínio público dos resultados de pesquisa das universidades públicas, impondo o seu resguardo e cuidado desde as atividades intermediárias até a efetiva obtenção do potencial bem público.

\section{CONCLUSÕES}

O presente trabalho buscou analisar a necessidade de apropriação da tecnologia desenvolvida no âmbito universitário, sobretudo a partir do contexto da inovação e da propriedade industrial nacional. Assim, inicialmente se destacou que o conceito legal de inovação previsto na Lei $\mathrm{n}^{\circ} 10.973 / 04$, para além de se relacionar com o resultado de uma atividade, aborda um gênero do qual a criação é espécie. Esta criação acaba se tornando o objeto mais concreto da Lei da Inovação, sendo que os bens mencionados na sua definição legal se encontram protegidos juridicamente por intermédio da Lei de propriedade industrial, comprovando a relação entre a inovação e a propriedade industrial desde sua definição legal. Além disso, relembrou-se que a propriedade industrial protege os investimentos em inovação, permitindo a sua exploração temporária em regime de monopólio. Ademais, além de ambos serem em conjunto indicadores do desenvolvimento econômico e social dos países, identificouse que as patentes representam um dos dois principais instrumentos de verificação da inovação internacional, ao lado do investimento nesta atividade.

Após a demonstração do diálogo entre inovação e propriedade industrial, constatou-se a relação destes elementos com as universidades públicas. Para tanto, demonstrou-se que o arranjo inovador nacional indica o predomínio das atividades de pesquisa e desenvolvimento de novas tecnologias pelas Universidades Públicas, tornando-se o principal potencial inovador e detentor de patentes no país. Com efeito, apurou-se que tanto o investimento estatal, quanto o número de pessoas envolvidas estão alocados prioritariamente nas universidades públicas. Como resultado, entre os dez principais depositantes de patentes no país, os nove primeiros são universidades públicas. Contudo, em contraste ao crescente estímulo à inovação e ao incremento do potencial inovador nacional, verificou-se que este potencial não se traduz na mesma proporção em efetiva inovação, e, por conseguinte, em patentes. Com efeito, conquanto o país esteja em $13^{\circ} \mathrm{em}$ publicações científicas, ocupa tão somente a $69^{\mathrm{a}}$ posição entre 127 países em termos de Inovação. Ademais, no âmbito internacional, realizou em 2017 aproximadamente $1 \%$ dos depósitos de patentes efetuados pelo país líder. Verificando os depósitos realizados exclusivamente no INPI, constatou-se que $74 \%$ dos pedidos são de estrangeiros. 
Buscando modificar este cenário e contribuir com a efetiva realização dos objetivos constitucionais, esta pesquisa se debruçou sobre a necessidade de proteção daqueles trabalhos que já são desenvolvidos no âmbito universitário, sobretudo em razão do contexto nacional e da sua atual participação no desenvolvimento tecnológico do país. No ponto, verificou-se a necessidade de apropriação do resultado das pesquisas tecnológicas desenvolvidas na universidade pública por meio da propriedade industrial, no intuito de contribuir para uma mudança cultural que vise ao estímulo e ao adequado tratamento do potencial inovador e da propriedade industrial como bem público.

De fato, embora não esteja especificamente entre as suas atividades, o contexto fático denota a preponderância da universidade pública na pesquisa e no desenvolvimento de novas tecnologias, não havendo como negar a sua importância no desenvolvimento social, econômico e tecnológico do país. Consequentemente, impõe-se o tratamento da pesquisa e a utilização de recursos públicos para sua realização como uma atividade pública potencialmente apropriável. Nesse sentido, o atual texto constitucional, modificado pela Emenda Constitucional n ${ }^{\circ}$ 85/2015, prevê no seu artigo 218, em igualdade de condições, a inovação e a pesquisa científica e tecnológica, presumindo-se a apropriação dos resultados das atividades como regra geral.

Ademais, verifica-se que por uma interpretação lógica, sistemática e teleológica do ordenamento jurídico, este acaba por exigir das universidades públicas, e de seus agentes envolvidos, a efetiva proteção das atividades que visem à inovação e de seu consequente resultado. Com efeito, a partir da busca do desenvolvimento e da soberania nacional, previstos no artigo $3^{\circ}$, II e artigo $1^{\circ}$, I, concretizados por meio dos artigos 218, 219, 219-A e 219-B, todos da CF; pela observância dos princípios da legalidade e da eficiência, estabelecidos no caput do artigo 37 da CF; em decorrência da importância do atendimento da propriedade industrial a uma finalidade social, decorrente do art. $5^{\circ}$, XXIX, XXII, XXIII e art. 170, II e III, todos da CF; pela previsão do art. 88, da Lei n $^{\circ}$ 9.729, o qual fundamenta a propriedade da universidade pública e consequentemente origina um bem público em que incide regime jurídico específico; tendo em vista a incidência dos princípios da supremacia e indisponibilidade do interesse público, bem como de deveres administrativos, tais como de zelo, eficiência, controle e prestação de contas na utilização e guarda de recursos públicos pelos agentes públicos que vinculam suas atividades; pela tendência de prestígio à administração pública gerencial, voltada ao controle de resultados, em detrimento da administração pública burocrática, focada no controle dos processos; pela imposição do sigilo das informações, decorrente do artigo $5^{\circ}$, XIX, XXXIII, XXXIV e LX, da CF, do art. 39 do TRIPS, dos artigos $7^{\circ}, \S 1^{\circ}, 22$ e, 23, VI, da Lei ${ }^{\circ}$ PIDCC, Aracaju/Se, Ano VIII, Volume 13 no 01, p.082 a 109 Fev/2019 | www.pidcc.com.br 
12.527/2011, do art. 195, XI e XII, da Lei n ${ }^{\circ}$ 9.279/1996, do artigo 116, VIII, da Lei 8.112/90, do artigo 327 do CP, e atualmente, de forma mais específica, pelo artigo 12 da Lei $\mathrm{n}^{\circ}$ 10.973/2004, exigindo a confidencialidade das informações e a autorização da universidade para sua divulgação; infere-se a orientação, como princípio, da apropriação da tecnologia, a qual, como regra, deve-se se sobressair ao domínio público dos resultados de pesquisa das universidades públicas, impondo o resguardo e o cuidado desde as atividades intermediárias para a obtenção de novas tecnologias como bens públicos.

Relembra-se, ainda, que respectiva apropriação não impede a utilização de outras formas de distribuição e acesso livre da tecnologia, tais como a autorização e licenciamento gratuito. Além disso, também se destaca que não há princípios absolutos, os quais devem ser aplicados com parcimônia e ponderação quando em conflito com outros princípios. Contudo, conforme se observou, a apropriação não se confunde com domínio público, já que, como bem apropriável, deverá ser objeto de proteção para posterior disposição livre ou limitada, de acordo com o interesse público. Assim, verifica-se a importância de um tratamento atento e responsável com o possível patrimônio intangível gerado no seio destas instituições, por meio do fomento da cultura da apropriação da tecnologia, no intuito de modificar o cenário fático atual e atender aos mandamentos normativos.

\section{REFERÊNCIAS}

ALBUQUERQUE, Eduardo da Motta. As múltiplas dimensões das patentes: notas a partir de um survey da literatura mainstream. Revista Análise Econômica. Ano 16, nº 29, p. 87-102, março. UFRGS, Porto Alegre. 1998.

ANDREASSI, Tales; ALBUQUERQUE, Eduardo da Motta e; MACEDO, Paulo Brigido Rocha; SBRAGIA, Roberto. Relação entre inovação tecnológica e patentes: o caso brasileiro. Revista de Administração. São Paulo v. 35, n. 1, p 63-71, janeiro/março 2000. Disponível em: $<$ https://gvpesquisa.fgv.br/sites/gvpesquisa.fgv.br/files/arquivos/andreassi__relacao_entre_in ovacao_tecnologica_e_patentes_o_caso_brasileiro.pdf $>$. Acesso em 04/04/2018.

BARBOSA, Denis Borges. Direito ao desenvolvimento, inovação e a apropriação das tecnologias após a Emenda Constitucional no 85 (2015). 2015. Disponível em:< http://www.denisbarbosa.addr.com/arquivos/200/inovacao/direito_ao_desenvolvimento_2015 .pdf $>$. Acesso em: 21 de agosto de 2017.

BARBOSA, Denis Borges. O Domínio do Público. 2011. Disponível em: $<$ http://denisbarbosa.addr.com/arquivos/200/propriedade/dominio_do_publico.pdf $>$. Acesso em $08 / 12 / 2018$. 
A APROPRIAÇÃO DA TECNOLOGIA PELA UNIVERSIDADE PÚBLICA BRASILEIRA E O DIÁLOGO ENTRE A INOVAÇÃO E A PROPRIEDADE INDUSTRIAL NO CONTEXTO NACIONAL

BARBOSA, Denis Borges. Patente como modelo de aperfeiçoamento em inovação. 2010. Disponível em:

$<$ http://www.nbb.com.br/pub/denis/patente_modelo _aperfeicoamento_\%20inovacao.pdf $>$. Acesso em 08/12/2018.

BARBOSA, Denis Borges. Domínio Público e Patrimônio Cultural. 2005. Disponível em: $<$ http://denisbarbosa.addr.com/bruno.pdf $>$. Acesso em 08/12/2018.

BARROS, Carla Eugênia Caldas. Manual de Direito Empresarial Multifacetado. Volume IV. Aracaju: PIDCC, 2016. Disponível em: <http://pidcc.com.br/br/manual-de-direitoempresarial-multifacetado-vol-iv>. Acesso em 14/08/2018.

BOCCHINO, Leslie de Oliveira [et al]. Publicações da Escola da AGU: Propriedade Intelectual - conceitos e procedimentos. Brasília: Advocacia-Geral da União, 2010.

BONACELLI, Maria Beatriz Machado; CARNEIRO, Ana Maria; GIMENES, Ana Maria Nunes. A universidade em um contexto de mudanças: integrando ciência, tecnologia e inovação. Revista de Propriedade Intelectual - Direito Contemporâneo e Constituição. PIDCC. Aracaju, ano V, Volume 10, $\mathrm{n}^{\mathrm{o}}$ 01, p. 115-133, fev./2016. Disponível em: $<\mathrm{http}$ ://pidcc.com.br/br/component/content/article/2-uncategorised/225-a-universidade-em-um-contexto-de-mudancas-integrando-ciencia-tecnologia-e-inovação>. Acesso em 11/06/2018. BRASIL. Ministério da Ciência, Tecnologia, Inovação e Comunicação. Estratégia Nacional de Ciência, Tecnologia e Inovação 2016-2022. Ciência, Tecnologia e Inovação para o Desenvolvimento Econômico e Social. Brasília. 2016.

CARVALHO. Matheus. Manual de Direito Administrativo. $3^{\text {a }}$ Edição. Salvador. Editora Juspodivum. 2016. 1183 p.

CROSS, Di; THOMSON, Simon; SIBCLAIR, Alexandra. Research in Brazil: A report for CAPES by Clarivate Analytics. Clarivate Analytics, 2018. Disponível em: $<$ htt ps://www.capes.gov.br/images/stories/download/diversos/17012018-CAPES-InCitesReportFinal.pdf $>$. Acesso em 25/05/2018.

CRUZ, Carlos Henrique de Brito. A. Universidade, a empresa e a pesquisa que o país precisa. Revista Humanidades, vol. 45, p.15-29, UNB. Brasília, 1999. Disponível em: $<$ https://www.ifi.unicamp.br/ brito/artigos/univ-empr-pesq-II.pdf>. Acesso em 21/09/2018.

DI PIETRO, Maria Sylvia Zanella. Direito Administrativo. $30^{\text {a }}$ edição. Editora Atlas. São Paulo, 2014.

ETZKOWITS, Henry. Hélice Tríplice. Universidade-Indústria-Governo. Inovação em Movimento. Porto Alegre. Editora PUCRS, 2009. 
GII. Índice Global de Inovação de 2017. A inovação nutrindo o mundo. 2017. Disponível em: $<$ https://www.globalinnovationindex.org/Download.aspx?file=/userfiles/file/reportpdf/GII\%2 02017\%20Portuguese\%20translation_WEB.pdf>. Acesso em 26/06/2018.

GUERREIRO, Marcelo da Fonseca, Apontamentos sobre a tutela patentária de medicamentos no Brasil. Revista de Informação Legislativa. Brasília. a. 46, n. 181, p 239-248, jan./mar. 2009. Disponível em: <https://www2.senado.leg.br/bdsf/bitstream/handle/id/ 194905/000861770.pdf? sequence=3>. Acesso em 10/04/2018.

GUSMÃO, Jose Roberto d'Affonseca. Natureza jurídica do direito de propriedade intelectual. São Paulo, 39 p., 1990. Disponível em: <http://www.glpi.com.br/noticiaspublicacoes/publicacoes-e-artigos/propriedade-intelectual/natureza-juridica-do-direito-depropriedade-intelectual/98>. Acesso em 03/08/2018.

INPI. Instituto Nacional da Propriedade Industrial. Indicadores de Propriedade Industrial 2017. Rio de Janeiro, 2017. Disponível em: $<$ http://www.inpi.gov.br/sobre/estatisticas/arquivos /pagina-inicial/indicadores-de-propriedade-industrial-2017_versao_portal.pdf $>$. Acesso em $10 / 08 / 2018$.

MAFRA, Francisco. Administração pública burocrática e gerencial. Âmbito Jurídico. Rio Grande, VIII, n. 21, maio 2005. Disponível em: <http://www.ambitojuridico.com.br/site/index.php?n_link=revista_artigos_leitura\&artigo_id=503>. Acesso em $15 / 12 / 2018$.

MCTIC. Ministério da Ciência, Tecnologia, Inovação e Comunicações. Indicadores Nacionais de Ciência, Tecnologia e Inovação 2017. 2017. Disponível em: $<$ https://www.mctic.gov.br/mctic/export/sites/institucional/indicadores/arquivos/Indicadores2017.pdf $>$. Acesso em 20/05/2018.

MEIRELLES, Helly Lopes. Direito Administrativo Brasileiro. 42 $2^{\mathrm{a}}$ edição. São Paulo: Malheiros, 2016.

MELlo. Celso Antônio Bandeira de. Curso de Direito Administrativo. 30a edição. Editora Malheiros. p. 1136. São Paulo, 2013.

OCDE. Organização para a Cooperação e Desenvolvimento Econômico. Manual de Frascati. Proposta de Práticas Exemplares para Inquéritos sobre Investigação e Desenvolvimento Experimental. G. C. Gráfica de Coimbra, Coimbra. 2007.

OCDE. Organização para a Cooperação e Desenvolvimento Econômico. Manual de Oslo. Diretrizes para coleta e interpretação de dados sobre inovação. $3^{\text {a }}$ Edição, FINEP, Brasília. 2006. 
A APROPRIAÇÃO DA TECNOLOGIA PELA UNIVERSIDADE PÚBLICA BRASILEIRA E O DIÁLOGO ENTRE A INOVAÇÃO E A PROPRIEDADE INDUSTRIAL NO CONTEXTO NACIONAL

OLIVEIRA, Fernando Cardoso Boaventura; AVELLAR, Ana Paula M. Análise do Desenvolvimento Tecnológico de Brasil, Rússia, Índia e China (BRIC): mapeamento dos indicadores de ciência e inovação. Revista Horizonte Científico. Vol. 3, n ${ }^{\circ}$ 1, p. 1-30, edição eletrônica, dez. 2009.

PATENSCOPE. Base de dados da OMPI. 2018. Disponível em: $<$ https://patentscope.wipo.int/search/en/result.jsf?query=\%28ANID:BR*\%20AND\%20CTR: WO\%29>. Acesso em 24/05/2018.

PAVIANI, Jayme; POZENATO, José Clemente. A universidade em Debate. Caxias do Sul, Universidade de Caxias do Sul, 1980.

PEREIRA. José Matias. A gestão do sistema de proteção à propriedade intelectual no Brasil é consistente?. Revista de Administração Pública. Vol. 45 (3), p. 567-590, maio/jun. Rio de Janeiro, 2011

PIMENTEL, Luiz Otávio. Propriedade Intelectual e universidade: aspectos legais. Florianópolis: Fundação Boiteux, 2005.

RAMOS, André Luiz Santa Cruz; GUTERRES, Thiago Martins. Lei de Propriedade Industrial Comentada: Lei 9.279, de 14 de maio de 1996. Salvador: Ed. Juspodivum, 2016. TEDESCHI, Patrícia Pereira. Inovação Tecnológica e Direito Administrativo. Dissertação (Mestrado em Direito). Faculdade de Direito. Universidade de São Paulo. São Paulo, p. 107.

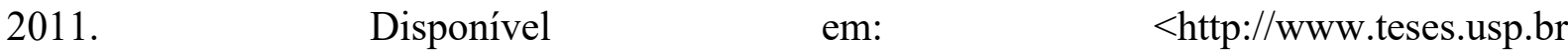
/teses/disponiveis/2/2134/tde-28082012-153145/pt-br.php>. Acesso em 10/10/2018.

SALERNO, Mario Sergio. A política industrial, tecnológica e de comércio exterior do governo federal. Revista Parcerias Estratégicas. Vol. 9, nº 19, p. 13-35, 2004.

VIOTTI, Eduardo B. Brazil: From S\&T to innovation policy? The evolution and the challenges facing Brazilian policies for science, technology and innovation. VI Globelics Conference. Mexico City, September 22-24, 2008. Disponível em: $<$ https://www.researchgate.net/publication/48267738_Brazil_From_ST_to_innovation_policy _The_evolution_and_the_challenges_facing_Brazilian_policies_for_science_technology_and _innovation>. Acesso em 18/11/2018.

WANDERLEY, Luiz Eduardo W. O que é Universidade. Coleção primeiros passos. 8. ed. São Paulo: Editora brasiliense, 1991. 85 p.

WIPO. Organização Mundial de Propriedade Intelectual. What is a patent? 2018a. Disponível em $<$ http://www.wipo.int/patents/en/index.html $>$. Acesso em 10/07/2018. 
WIPO. Organização Mundial de Propriedade Intelectual. Annexes to WIPO press release PR/2018. 2018b. Disponível em: <http://www.wipo.int/export/sites/ www/pressroom/en/documents/pr_2018_816_annexes.pdf\#annex1>. Acesso em 15/06/2018. 